\title{
Male-killing selfish cytoplasmic element causes sex-ratio distortion in Drosophila melanogaster
}

\author{
HORÁCIO MONTENEGRO $\dagger$, WILMA N. SOUZA $\dagger$, DOMINGOS DA SILVA LEITE $\ddagger$ \\ \& LOUIS B. KLACZKO† \\ $\dagger$ Departamento de Genética e Evolução and $\ddagger$ Departamento de Microbiologia e Imunologia, Instituto de Biologia, \\ Universidade Estadual de Campinas, UNICAMP, Campinas, CEP 13083-970, Sao Paulo, Brazil
}

\begin{abstract}
Sex ratio distortion induced by a male-killing agent has been found to affect Drosophila melanogaster. The trait was discovered accidentally in a collection of flies from markets in Campinas, São Paulo State, Brazil. Repeated crosses with Canton-S males (for 15 generations to date) and successful transmission using the injection of macerates of sex ratio flies, have shown that the trait is inherited maternally, is cytoplasmic and is infectious. Crosses with strains marked with the visible mutation white and viability experiments at pre-adult stages of development, indicate that the skewed sex ratio results from male mortality before hatching. Males do not transmit the trait to their progeny.
\end{abstract}

Keywords: cytoplasmic inheritance, sex ratio, Spiroplasma, SRO.

\section{Introduction}

Selfish genetic elements (SGE) produce departures from Mendelian proportions and increase their own frequencies, often at the expense of host fitness (Werren et al., 1988). Selfish cytoplasmic elements (SCE) are a special case of SGE. Since only females transmit SCE, they suffer strong selection to deviate the sex ratio or resource allocation towards females. This is usually accomplished through male sterility in plants (Saumitou-Laprade et al., 1994) and other endosymbionts that alter the sex ratio away from $19: 1 \hat{\jmath}$, including male killers (Williamson \& Poulson, 1979; Hurst, 1993).

Sometimes the progenies of females collected in the wild show an exceptional excess of females - a trait commonly called 'sex-ratio' (SR). The first SR cases analysed were determined paternally and produced by driving $\mathrm{X}$ chromosomes in Drosophila obscura (Gershenson, 1928) and D. pseudoobscura (Sturtevant \& Dobzhansky, 1936). Maternally inherited SR traits were described later in several Drosophila species (for a review see Hurst, 1993). All were inherited cytoplasmically, as shown by the male killing (MK) at the embryonic stage. In one case, the SR trait was found to be infectious (Malogolowkin \& Poulson, 1957). Howard (1942) reported an intriguing and complex picture in Armadillium vulgare that he ascribed to the

*Correspondence. E-mail: lbk@unicamp.br meiotic drive of the sex chromosomes in females $(\mathrm{Z}$ or $\mathrm{W}$ drive), which produced broods with an excess of males and/or females. More recently, Juchault et al. (1992) explained the situation as two selfish sex-ratio factors, one cytoplasmic and the other one with predominantly, but not exclusive, maternal transmission. Cavalcanti et al. (1958) noted that the simultaneous action of cytoplasmic factors and nuclear modifiers could blur interpretation of the results. Thus, only after obtaining several homozygous strains in $D$. prosaltans were these authors able to explain the observed SR in this species as being a consequence of a cytoplasmic male-killer and a recessive nuclear gene which disrupts transmission of the cytoplasmic factor. Moreover, parthenogenesis can also produce all-female broods (Lanier \& Oliver, 1966; Stouthamer \& Werren, 1993). Thus, if one attempts to explain a newly observed SR in terms of male-killing SCE all other possible causes must be ruled out.

Hurst (1991) proposed a distinction between early and late MK, on the grounds that the evolutionary strategies underlying these two phenomena were completely different. Early male-killers have an advantage in that kinselection favours clonal relatives of the suicide element located in females whereas with late MK there is a chance of horizontal transmission to uninfected females. In Drosophila, early MK agents have been reported in nine species: D. bifasciata (Magni, 1953), D. prosaltans (Cavalcanti et al., 1958), D. borealis (Carson, 1956), D. willistoni, D. paulistorum, D. equinoxialis, D. nebulosa, 
D. robusta (Williamson \& Poulson, 1979) and D. roehrae (Vaz et al., 1998). Only in the willistoni group has the causative agent been identified, as a Spiroplasma (Class Mollicutes, Order Mycoplasmatales) (Hackett et al., 1986).

So far no male-killing endosymbiont has been found in any natural population of D. melanogaster (Fitz-Earle \& Sakaguchi, 1986; Hurst, 1993). We report here for the first time the occurrence of a sex-ratio trait in this species which is maternally inherited, infectious and caused by early MK.

\section{Materials and methods}

\section{Collection, maintenance and selection of SR strain}

In order to perform an experiment not related to sex ratio distortion, we collected adult flies in two markets in Campinas, São Paulo State, Brazil, on 16 July 1997. To set up isofemale lines, the females were placed individually in bottles with standard cornmeal medium, at room temperature. After 7 days, they were etherized to death and placed individually in wells of ELISA plates containing alcohol $70 \%$. The progenies were counted after all adults had hatched. In orfer to distinguish $D$. melanogaster from its sibling species, $D$. simulans, the offspring were examined and the species separated according to the genital arch of the males. Forty-three lines were set up. Five did not produce offspring; 35 were found to be $D$. simulans; and only three were D. melanogaster, one of which - strain VFA11 - had no males among more than 80 flies examined.

We took two samples of 13 flies each from this strain and crossed them to Canton-S males and to males from another strain (VFA-9). In both cases, no males appeared in the progenies. From then on, all experiments were performed using flies from the VFA$11 \times$ Canton-S cross (hereafter called SR).

Initially, the stocks were maintained through mass transfer of SR females and the addition of Canton-S males. Nevertheless, after a few generations, the male frequency gradually rose from $0 \%$ to about $30 \%$. At this point, we started a selection procedure to maintain the SR strain. In the first generation, 14 virgin SR flies were crossed individually to two Canton-S males, after which, at each generation, we chose five females from each of the four most fertile lines and with the most skewed sex ratios (20 females in total). These were crossed individually to two Canton-S males. Females from later broods of the selected lines were subsequently used to start a new generation. From the seventh generation onwards, the total number of selected females varied from 5 to 15 , but always with five females per selected line.

\section{Crosses to males with visible mutations}

An altered sex ratio may have several aetiologies, including feminization of genetic males, parthenogenesis, male-killing or gametic selection. To rule out the first two hypotheses in the present case we crossed SR females with males from a white (recessive X-linked mutation) strain, and back-crossed the daughters to white males. If no white females appeared in the $F_{1}$ feminization was discarded. If the back-cross progeny showed the white mutation, parthenogenesis was excluded. However, these crosses cannot differentiate gametic selection from male-killing.

\section{Egg-larva, larva-pupa and pupa-adult viability}

The next step was to distinguish between gametic selection - male zygotes not being formed (primary sex ratio) - from the killing (early or late) of male zygotes (secondary sex ratio). To do so, we compared the mortality rates at various developmental stages of normal and SR strains. After collecting eggs and larvae, the egg-larva, larva-pupa and pupa-adult hatch rates were scored. Eggs were collected from slides covered with coloured medium on which the flies had been allowed to oviposit for up to $8 \mathrm{~h}$, when slides were replaced. The eggs were picked just after slide removal, and were maintained at $24^{\circ} \mathrm{C}$. Larvae and unhatched eggs were counted $30 \mathrm{~h}$ after egg collection. The larvae were collected as described for eggs, but the slides were changed every $24 \mathrm{~h}$ : the larvae were then collected after a further $24 \mathrm{~h}$ and transferred to small vials containing $10 \mathrm{~mL}$ of medium $(100 \mathrm{~mL}$ distilled water, $4 \mathrm{~g}$ agar, $16 \mathrm{~g}$ dry yeast and $5 \mathrm{~g}$ sugar) with 10 larvae per vial, and maintained at $24^{\circ} \mathrm{C}$. Pupae and adults were counted after at least 12 days; the adults were also sexed.

\section{Demonstration of infectivity}

Horizontal transfer is a test that can help to link an SR trait to an infectious agent (Ebbert, 1993). Because obligate endosymbionts are often fastidious to culture, thus hindering the fulfilment of Koch's postulates, this test is useful in revealing the nature of the trait at the outset of a study. We therefore used injections of macerated flies to determine whether an infectious agent was the cause of the observed sex ratio condition.

For this, we used a slight modification of the L'Heritier's (1958) method. In the first experiment, a macerate of 100 15-20-d-old SR flies was centrifuged in $1 \mathrm{~mL}$ of Waddington's modified Drosophila Ringer solution (solution A contains $\mathrm{NaCl} 37.5 \mathrm{~g}, \mathrm{CaCl}_{2} 1.0 \mathrm{~g}$ and, $\mathrm{KCl} 0.5 \mathrm{~g}$ in $500 \mathrm{~mL}$ of distilled water and solution B contains $\mathrm{NaHCO}_{3} 1.0 \mathrm{~g}$ in $500 \mathrm{~mL}$ distilled water; the 
solutions are autoclaved separately and mixed when needed in a ratio of one part of $\mathrm{A}$, one part of $\mathrm{B}$ and eight parts of sterile distilled water) for $15 \mathrm{~min}$ at 3000 4500 r.p.m. In the second experiment, 150 flies were macerated. The supernatant, kept on ice, was injected into etherized 1-7-d-old virgin females, from normal Canton-S strains. As a control, a supernatant of Canton-S females, obtained in the same way, was injected into Canton-S females. The macerate was injected at the junction between the thorax and the scutelum. Each recipient fly received approximately $0.1 \mu \mathrm{L}$. Injected females were left to recover for one day in separate vials, after which two or three Canton-S males were added. The vials were changed at intervals ranging from 3 to 7 days, until the fly died or did not produce offspring.

\section{Tests of males}

The males that appeared in SR lines were crossed to Canton-S females to establish whether males transmit the sex ratio condition to their broods. We used two controls. In the positive control, SR females, sisters of the males being tested, were crossed to Canton-S males. In the negative control (normal sex ratio), Canton-S females were crossed to Canton-S males. In a few cases, in addition to SR females from the same brood in which males appeared, SR females from a later brood were tested. All crosses were performed as single-pair matings so that the progenies could be scored as single female productions. Pairs were put into small vials with approximately $20 \mathrm{~mL}$ of cornmeal medium and were moved to new vials at variable intervals, but always allowing the scoring of at least three broods. If the progeny had a sex ratio of 3 females: 1 male (or more skewed) it was considered as SR progeny (Sakaguchi \& Poulson, 1963). If the progeny started with an even sex ratio and later showed an SR ratio (as defined above), it was considered to be a progressive SR progeny. The remaining cases were considered normal progenies.

\section{Results}

\section{Maintenance and selection of SR strain}

In order to maintain SR, we carried out a selection procedure for 15 generations, back-crossing the females to Canton-S males at each generation. This resulted in a strain with more than $99.9 \%$ of the Canton-S genetic background. Table 1 shows the total progeny in each generation, along with the number of producing females and SR females per generation. To date, 14571 flies have been counted, with 14463 females and only 108 males $(0.7 \%)$. Among 154 individual progenies scored,

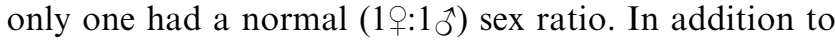
the normal strain, males also appeared in $11 \mathrm{SR}$ lines, with the highest male frequency being 15\% (36ㅇ, 4^), always in the first broods (males were absent in later broods). This trend was also observed in other instances in which males appeared.

\section{Crosses to males with visible mutations}

Overall, the results from the crosses with white males indicated that fertilization was occurring, whereas feminization was not. In the first generation of SR females individually crossed to white males, there was neither a single white fly nor a male in the progeny
Table 1 Results from the selection procedure used for sex ratio maintenance

\begin{tabular}{lcccc}
\hline Generation & $\begin{array}{c}\text { Ooffspring } \\
\text { produced }\end{array}$ & $\begin{array}{c}\text { ô Offspring } \\
\text { produced }\end{array}$ & $\begin{array}{c}\text { of Producing } \\
\text { SR progenies }\end{array}$ & $\begin{array}{c}\text { ơ Producing } \\
\text { normal progenies }\end{array}$ \\
\hline 1 & 492 & 0 & 8 & 0 \\
2 & 1569 & 8 & 18 & 0 \\
3 & 3057 & 0 & 18 & 0 \\
4 & 3384 & 4 & 20 & 0 \\
5 & 1302 & 0 & 17 & 0 \\
6 & 937 & 1 & 16 & 0 \\
7 & 653 & 0 & 14 & 0 \\
8 & 832 & 0 & 14 & 0 \\
9 & 150 & 0 & 5 & 0 \\
10 & 292 & 10 & 5 & 0 \\
11 & 605 & 0 & 5 & 0 \\
12 & 52 & 0 & 2 & 0 \\
13 & 756 & 0 & 5 & 1 \\
14 & 160 & 2 & 4 & 0 \\
15 & 222 & 83 & 3 & 0 \\
\hline
\end{tabular}


Table 2 Results of crosses of SR females to males from a white strain. In the first generation eight females of the VFA-11 strain (SR) were crossed to white males. From the $\mathrm{F}_{1}$, eight females were backcrossed to white males

\begin{tabular}{|c|c|}
\hline $\begin{array}{l}\mathrm{F}_{1} \\
q \mathrm{VFA}-11 \times \hat{\jmath} \text { white }\end{array}$ & $\begin{array}{c}\text { Backcross } \\
q(q \text { VFA-11 } \times \widehat{\jmath} \text { white }) \times \widehat{\jmath} \text { white }\end{array}$ \\
\hline 170 우 + & $400 q+, 425 q$ white \\
\hline
\end{tabular}

(Table 2, summarizes the results for 170 flies, with pooling of the progenies). If feminization occurred, one would expect some of the females to be white. In the second generation - backcross to white males - 825 flies were examined. All were females, with 400 being wild type and 425 white, in agreement with the expected 1:1 Mendelian ratio among females. This unequivocally shows that fertilization occurred and that the sex-ratio trait observed is not a result of parthenogenesis.

\section{Viability experiments}

The egg-larva viability in the SR strain was half $(41.2 \%)$ that of the normal strain $(82.7 \%)$ (Table 3). However, the larva-pupa and pupa-adult viabilities were the same in the two strains (Table 4). The larva-adult viability in the normal strain was $92.8 \%$, while in the SR strain it was $94.5 \%$. These results show that male embryos are dying very early in the development and this is probably the cause of the sex-ratio deviation. Moreover, females seem to be little - or not at all — affected by the killing agent.

\section{Injection experiments}

Initially, the injection experiments did not yield encouraging results at first sight. In the first experiment, not a single control fly produced sufficient offspring for comparison with SR injected flies. None of the 13 females that produced enough progeny had overall SR broods. Only one at the very end of its life produced SR broods (a progressive SR fly). The total production did not differ significantly from a 1 이수 $\widehat{o}$ sex ratio (780우, $\left.714 \hat{\jmath}, \quad \chi^{2}=2.92, \quad P=0.09\right)$. Because no control remained, only a few tests were performed to account

Table 3 Egg-larva viability in normal (Canton-S) and SR strains

\begin{tabular}{lcc}
\hline Strain & Eggs counted & Larvae hatched (\% of total) \\
\hline SR & 153 & $63(41.2 \%)$ \\
Canton-S & 162 & $134(82.7 \%)$ \\
\hline
\end{tabular}

Table 4 Larva-pupa and pupa-adult viability in normal and SR strains

\begin{tabular}{lrrc}
\hline Strain & $\begin{array}{c}\text { Larvae } \\
\text { tested }\end{array}$ & $\begin{array}{c}\text { Pupae formed } \\
(\% \text { of larvae) }\end{array}$ & $\begin{array}{c}\text { Adults hatched } \\
(\% \text { of pupae })\end{array}$ \\
\hline SR & 90 & $87(96.7 \%)$ & $84 \%$ and $1 \delta(97.7 \%)$ \\
Canton-S & 140 & $131(93.6 \%)$ & $72 \%$ and $58 \widehat{(99.2 \%)}$ \\
\hline
\end{tabular}

for transmissions to subsequent generations. Nevertheless, two injected females - one of them being the one mentioned above - gave origin to lines that eventually became SR. One of the strains was maintained without producing males (more than $98 \%$ females) for five generations, after which it was lost. The other has been maintained by the same procedure used in the selection experiment. Currently, this line is in the ninth generation, with skewed progenies (more than $99 \%$ females).

In the second experiment all of the lines injected with SR macerated flies and their controls produced normal progenies, except one female in the experimental group. It started with a normal sex ratio and developed into a skewed one [the consecutive counts were 73( + ):63( 3 ); $64: 52 ; 63: 17 ; 2: 0]$. In the second generation we tested 47 females of the experimental group and 30 from the controls (data not shown). Only one female - from the experimental group - was SR (36우워). Using this fly progeny, we established an SR strain that has been kept for eight generations with a consistently skewed sexratio (more than $92 \%$ females).

\section{Tests of males}

The crosses with males that appeared in SR lines vs. Canton-S females did not produce any SR line, and were not significantly different $\left(\chi^{2}=1.52, P=0.22\right)$ from the sex ratio in the control lines of Canton-S females $\times$ Canton-S males. In contrast, $72 \%$ of the crosses involving SR females produced SR or progressive SR progenies (Table 5). This shows that only females transmit the SR condition to their progenies.

\section{Discussion}

During a collection at markets in Campinas, São Paulo State, Brazil, we found a D. melanogaster female that produced highly skewed progeny with an excess of females. This distorted sex ratio has been maintained for 15 generations by outcrossing SR females to males of a normal laboratory strain, showing that the trait is maternally inherited. The maternal inheritance and the transfer of SR by the injection of macerates of SR flies into Canton-S normal flies shows that a selfish cytoplasmic element caused the SR. The results of crosses to 
Table 5 Results of male transmission tests (ratios expressed in $+:{ }^{\wedge}$ )

\begin{tabular}{|c|c|c|c|}
\hline & \multicolumn{3}{|c|}{ Progressive } \\
\hline & $\mathrm{SR}+9$ & $\mathrm{SR}+$ & Normal $q$ \\
\hline q Canton-S $\times \underset{0}{ }$ Canton-S & 0 & 0 & $21(3226: 3078)$ \\
\hline$q$ Canton-S $\times \underset{\text { ô }}{\mathrm{SR}}$ & 0 & 0 & $24(3127: 3118)$ \\
\hline q $\mathrm{SR} \times \hat{0}$ Canton-S & $36(5558: 19)$ & $5(809: 371)$ & $16(2595: 2392)$ \\
\hline
\end{tabular}

white males, together with the fact that the hatching rate of SR lines was half of the normal lines, strongly suggests that SR distortion resulted from the early death of male embryos. The present case shares some features with other reports of MK instances: incomplete transmission, occurrence of progressive SR females, which is rarer than reversion to normal females or full transmission (Ebbert, 1993), and early broods, which are more prone to contain males and uninfected females (Ebbert, 1991).

The present finding raises up to 10 the number of Drosophila species known to be affected by MK agents. It is possible that other Drosophila species may bear them. However, the persistence of MK agents within drosophilids has not yet been well explained. Data are still lacking to support the supposed advantages of resource reallocation, avoidance of inbreeding and horizontal transmission that could result from killing males and compensate incomplete symbiont transmission (Ebbert, 1993; Hurst, 1993).

The nature of the MK agent described here remains to be investigated. D. melanogaster was the recipient species at various $\mathrm{MK}$ transfer experiments involving spiroplasmas that infect the willistoni group (review in Williamson \& Poulson, 1979). Whether any such transfers later resulted in a spread to natural populations, has not been investigated. It is tempting to speculate that the androcidal agent of $D$. melanogaster is an escape from any of these experiments.

Several questions arise from the finding of the D. melanogaster MK agent. Are the androcidal agents in $D$. melanogaster and in the D. willistoni group species the same? If so, was it a natural transmission? Or, is this finding a consequence of the experiments of Poulson and coworkers in the early MK studies? Will the element persist in the population, or will it go extinct?

\section{Acknowledgements}

It is a pleasure to acknowledge Dr O. H. Pavan's help with the injection system. Carlos A. C. Andrade and Hermes F. Medeiros gave us insightful suggestions during the execution of this work. We received financial support from: Fundação de Amparo à Pesquisa do Estado de São Paulo (FAPESP), Conselho Nacional de
Desenvolvimento Científico e Tecnológico (CNPq), Coordenação de Aperfeiçoamento de Pessoal de Nível Superior (CAPES) and Fundo de Apoio ao Ensino e Pesquisa (FAEP-UNICAMP).

\section{References}

CARSON, H. L. 1956. A female-producing strain of Drosophila borealis Patterson. Drosoph. Inf. Serv., 30, 109-110.

CAVAlcanti, A. G. L., FALCÃO, D. N. AND CASTRO, L. E. 1958. The interaction of nuclear and cytoplasmic factors in the inheritance of the 'sex-ratio' character in Drosophila prosaltans. Univ. Brasil Publ. Fac. Nac. Filos. Série Cient., 1, 1-54.

EBbert, M. A. 1991. The interaction phenotype in the Drosophila willistoni-spiroplasma symbiosis. Evolution, 45, 971-988.

EBBERT, M. A. 1993. Endosymbiotic sex ratio distorters in insects and mites. In: Wrensch, D. L. and Ebbert, M. A. (eds) Evolution and Diversity of Sex Ratio in Insects and Mites, pp. 150-191. Chapman \& Hall, New York.

FITZ-EARLE, M. AND SAKAGUCHI, B. 1986. Sex ratio distortion in populations and its possible role in insect suppression: experimental studies with strains of Drosophila melanogaster carrying cytoplasmically-inherited male-killing spiroplasmas. Jap. J. Genet., 61, 447-460.

GERSHENSON, S. 1928. A new sex-ratio abnormality in Drosophila obscura. Genetics, 13, 488-507.

HACKETT, K. J., LYNN, D. E., WILliAMSON, D. L., GINSBERG, A. S. AND Whitcomb, R. F. 1986. Cultivation of the Drosophila sexratio spiroplasma. Science, 232, 1253-1255.

HOWARD, H. W. 1942. The genetics of Armadillium vulgare Latr. II. Studies on the inheritance of monogeny and amphogeny. J. Genet., 44, 143-159.

HURST, L. D. 1991. The incidences and evolution of cytoplasmic male killers. Proc. R. Soc. B, 244, 91-99.

HURST, L. D. 1993. The incidences and evolution of cytoplasmic sex ratio distorters in animals. Biol. Rev., 68, 121-193.

JUCHAUlt, P., RIGAUD, T. AND MOCQUARD, J. P. 1992. Evolution of sex-determining mechanisms in a wild population of Armadillium vulgare Latr. (Crustacea, Isopoda): competition between two feminising parasitic sex factors. Heredity, 69 , 382-390.

LANIER, G. N. AND OLIVER, J. H. JR. 1966. 'Sex-ratio' condition: unusual mechanisms in bark beetles. Science, 153, 208-209.

L'HERITIER, P. 1958. The hereditary virus of Drosophila. $A d v$. Virus Res., 5, 195-245.

MAGNI, G. E. 1953. 'Sex-ratio': a non-Mendelian character in Drosophila bifasciata. Nature, 4367, 81. 
MALOGOLOWKIN, C. AND POULSON, D. F. 1957. Infective transfer of maternally inherited abnormal sex-ratio in Drosophila willistoni. Science, 126, 32.

SAKAGUCHI, B. AND POULSON, D. F. 1963. Interspecific transfer of the 'sex-ratio' condition from Drosophila willistoni to D. melanogaster. Genetics, 48, 841-861.

SAUMitou-LAPRADE, P., CUGUEN, J. AND VERnET, P. 1994. Cytoplasmic male sterility in plants: molecular evidence and the nucleocytoplasmatic conflict. Trends Ecol. Evol., 9, 431-435.

Stouthamer, R. AND werRen, J. H. 1993. Microbes associated with parthenogenesis in wasps of the genus Trichogramma. J. Invert. Pathol., 61, 6-9.
STURTEVANT, A. H. AND DOBZHANSKy, T. 1936. Geographical distribution and cytology of 'sex ratio' in Drosophila pseudoobscura and related species. Genetics, 21, 473-490.

vaz, S. C., Vibranovski, M. D. AND CARvalho, A. B. 1998. Sexratio citoplasmático em Drosophila roehrae. Genet. Mol. Biol., 21 (Suppl.), 260.

WERREN, J. H., NUR, U. AND WU, C.I. 1988. Selfish genetic elements. Trends Ecol. Evol., 3, 297-302.

WILLIAMSON, D. L. AND POULSON, D. F. 1979. Sex ratio organisms (spiroplasmas) of Drosophila. In: Whitcomb, R. F. and Tully, J. G. (eds) The Mycoplasmas, Vol. 3, pp. 175-208. Academic Press, New York. 